\title{
Rerouting Digital Transformations Six Cases in the Airline Industry
}

\author{
Anne Maike Somsen \\ University of Amsterdam \\ annemaike@gmail.com \\ Daan Langbroek \\ KLM Royal Dutch Airlines \\ daan.langbroek@klm.com
}

\author{
Hans Borgman \\ University of Amsterdam \\ h.p.borgman@uva.nl
}

\author{
Chintan Amrit \\ University of Amsterdam \\ c.amrit@uva.nl
}

\begin{abstract}
The purpose of this study is to understand how and why success criteria evolve in the course of a digital transformation initiative. Evolving success criteria can cloud planning processes and lead to post-hoc rationalizations, an observation that is often made but the underlying processes are hardly researched. This exploratory study does so by employing a qualitative approach with six embedded case studies of different digital transformation initiatives (DTIs) within a large European airline company. Our findings show how traditional business case approval practices, the degree of involvement of different stakeholders -each using different metrics-, the closeness in collaboration between these stakeholders and lastly the degree to which key-users embrace the digital solution during a DTI, all contribute to evolving success criteria. A discussion of the findings and limitations, implications for practice and suggestions for future research conclude the article.
\end{abstract}

\section{Introduction}

Digitally enabled organizations outperform the competition and are more poised to meet the future head-on [1]. Organizational change has been a prerequisite to stay competitive that is encouraging companies to be in constant change [3]. In order to do so, new initiatives and technologies need to be introduced that influences all aspects of the business [4]. Organizations have never been at such pressure dealing with processes of change that is constantly forcing them to adapt to new situations at an high speed [5]. We call this process of change the digital journey, it accommodates the transformation towards a state of the industrial internet or Industry 4.0 [6], Industrial Value Chain Initiative [7] or Smart Industry [8].

A digital transformation in a company is accompanied with elements of uncertainty and difficulty for many decision makers [9]. It may not always be clear upfront what kind of value a digital transformation initiative (DTI) will bring to an organization due to its exploratory character. Nevertheless, executives want to understand the potential value and success criteria of a DTI in order to determine its return on investment (ROI). Success criteria are described as "those few things that must go well to ensure success" [10]. Defining success of new initiatives has always been a challenge due to the number of stakeholders involved, who all have different objectives. It is therefore measured and perceived in different ways [11]. Measuring success is complex, an initiative is hardly ever considered as a total success or failure for all stakeholders during all phases in the project life cycle. Despite the initial success criteria of a DTI not being always fulfilled, stakeholders still consider their DTIs as successful.

Therefore, the goal of this research is to determine the success criteria of digital transformation initiatives.

Due to the contemporary character of digital transformation, little research has been done so far on this topic. We explored the phenomenon in its natural context within six embedded case studies. The six embedded case studies, representing DTIs, have two main characteristics: they are performed with an agile way of working and include new technologies from which its success gradually emerged. Most organizations undertaking a digital transformation implement an agile way of working in order to welcome changing requirements, since agile processes harnesses change as a competitive advantage [13]. One of the methods to adopt an agile way of working is Scrum. Scrum is a framework in which people address complex adaptive problems [14]. The research goal is grounded in available literature and is empirically explored from three perspectives: a product manager $(\mathrm{PM})$, a product owner $(\mathrm{PO})$ and a key-user (K). Within this framework, a product manager complies to the initial success criteria at the approval of a DTI. The product owner executes this plan, together with one or more product developments teams, to realize the digital product. The current way of working of a key-user is changing with the 
implementation of digital solutions. In order to investigate DTIs in more detail our study consists of:

- A literature review, aimed at deriving propositions that contributes to understanding the success criteria of digital transformation initiatives.

- An exploration of six DTIs using interviews, coding and analysis.

Our objective is to create new insights that can support various stakeholders to improve their understanding, assessment and management of the success of DTIs. The contribution of this study is both in the derivation and formulation of the propositions as well as in the empirical exploration that helps understand why and in what form DTIs could bring success to an organization. It also contributes to the academic debate and identification of future areas of research.

\section{Literature and Theoretical Background}

\subsection{Digital Transformation Initiatives}

A recent piece of research conducted by LiereNetherler et al. [15] delved into the concept of digital transformation in a broad and comprehensive manner. Different databases were used to search through the AIS Senior Scholars' basket of eight journals, the main leading journals in Information System (IS) research [16]. Their broad overview included search terms such as "digital transformation", "digitization", "digitalization" or "industrial internet". 67 articles were identified on digital transformation from which many could not be allocated to a specific research stream, showing the wide focus of digital transformation and illustrating digital transformation as an extensive topic in IS research. The effect arising from digital transformations differs from other IS innovations [17]. Digital transformations go beyond the technical process and play an important role for socio-technical structures, making the process different from the adoption of other new technologies $[9,12]$. This new use of digital technologies in the working environment is increasing, and challenges companies to adapt their culture, mindset, and competencies to the new digital way of working [18].

In this regard, a DTI can be understood as a Technological Transition (TT), as explained and defined by Geels [19]. A TT is characterized as a major technological transformation in the way societal functions are fulfilled, stemming from a particular perspective on technology from sociology. Technology by itself has no power, it does not do anything on its own. However, when combining technology with human agency, or by associating it with social structures and organizations, technology fulfils various functions. A DTI, similar like a TT, does not only involve a technological change, but also the ability to change other elements such as user practices, or even carrying a symbolic meaning like freedom or individuality. In other words, a TT consists of a change from one socio-technical configuration to another, involving substitution of technology, as well as changes in other elements. Implementing new technologies like digital solutions and understanding its success can be difficult due to the mismatch with the established socio-institutional framework in which current practices are aligned with the existing technology [20]. Meaning that the consequences of only changing the technology and addressing the neglect of accompanied practices will cause the process of defining DTI success to be even more complicated. Rather than seeing a DTI as a project with a clear beginning and ending, but as an ongoing process requiring a transformation with accompanied practices from which its success will gradually emerge, could help in understanding its potential success.

\subsection{Measuring Success}

Apart from success in a more traditional sense, revolving around adherence to planned quality, time and costs, known as the iron triangle or triple constraint [21-23], other success criteria have been suggested in the literature. These include specific objectives or expectations, the rate of improvement, enjoyment, better relationships, new business opportunities, organizational efficiency and effectiveness, improved trust, attitudes towards technology, actual system use, improved teamwork, and individual as well as organization impact [23-27]. Now, working within agile environments and the exploratory character of DTIs, success criteria tend to emerge during a DTI. These emerging success criteria of a DTI are equally as important as initial success criteria and are more challenging to observe, isolate, measure and quantify. But they are key for developing an understanding on the success of a DTI.

\subsection{Research Propositions}

Holding on to this reasoning, five research propositions have been derived from the literature. The first proposition deals with the existence of 
evolving success criteria during DTIs - labeled - $P O$ Success criteria evolve during DTIs.

\subsubsection{Stakeholder View}

At the start of a DTI (the approval stage), like any other initiative, certain expectations are set by different stakeholders and translated into a proposal or business case. Particularly measurable and quantitative expectations are agreed upon in order to receive the required investment to carry out the plan. It might occur that promises are made that set (too) high expectations in order to acquire the necessary funding. This mechanism is highly influenced by power and politics in an organization [28]. "The process by which decisions are made by people in an organization" is defined as politics [29]. In most cases, traditional project management maintains a stage-gate approach. In each stage the project is reviewed and assessed. But more importantly; senior managers give the approval for going to the next stage [30]. In those non-agile environments, initial success criteria are set and not flexible, implying that not meeting these criteria will result in failure. Most executives assess success based on the proposals' initial and more traditional success criteria and apply those to DTIs as well. This leads to proposition P1 - DTI success criteria evolve more when the proposal at the approval stage derives from traditional business cases.

All DTIs occur simultaneously and contribute to the digital transformation as a whole. Various stakeholders are involved and concerned with their own agenda of success. Deciding upon 'when' a DTI is regarded as successful is quite a dilemma since different dimensions mean different things to different stakeholders at different times for different initiatives [24]. For example, within the framework of Scrum there are many dimensions that can determine progress such as sprints, retrospectives, demos and so on [14]. This proposition will focus on what kind of metric or unit of success different stakeholders will refer to, in order to understand what the DTI success entails. This leads to proposition $P 2$ - Different stakeholders $(P M / P O / K)$ express DTI success in different metrics.

\subsubsection{Product versus Process}

A DTI is regarded as a TT, accompanied with a digital solution (the product) that replaces the old system, or adds new tasks to the current work and practices. A digital solution within a DTI can be made up of many forms of technology such as social media, mobile, analytics or embedded devices [31] and comes with a new way of working. As previously mentioned, using a new form of technology influences the product itself but also the socio-technical structures. Defining success of a system (the product), or in this case a digital solution, can be done through evaluating the following interrelated dimensions, with certain proposed associations between them. It can be evaluated in terms of information quality, service quality and system quality, and these characteristics will affect the subsequent use, intention to use and user satisfaction [32]. Certain benefits will derive as a result of using the system, called net benefits; net benefits will influence user satisfaction and the further use. This proposition will explore what kind of net benefits will derive from using a new digital solution, leading to P3 - The degree to which key-users embrace the digital solution triggers stronger evolving success criteria.

Traditional product development such as a waterfall approach is heavily frontloaded since the entire development of the product is planned prior to the project execution. In this sense, the customer is expected to specify the product in detail which makes the product itself fully predictable. Only a few iterations exist in the entire process and communication relies strongly on formal channels. This makes traditional product development a bit bureaucratic and a mainly linear process. On the contrary, agile product development frameworks, such as Scrum, are more flexible and involve less explicit rules or stiff processes in terms of communication. The agile approach builds prototypes in short iterations and gathers user feedback by presenting working product increments [33, 34]. Since close team collaboration occurs on a daily basis, in addition to heavy customer integration accompanying the processes, it is expected that success criteria will emerge from this closer collaboration. It has already been proven that client satisfaction is a key factor that affects project and process success [11]. This leads to proposition $P 4$ Success criteria evolve more when the collaboration between $\mathrm{PM} / \mathrm{PO} / \mathrm{K}$ is closer.

\section{Research Methodology}

\subsection{Case Study Setting and Description}

The airline industry has undergone a profound transformation over the past few decades [35]. The origin lies within the deregulation of the airline 
industry that started in the late 1970s, which led to the entry of new actors and a subsequent increase in competition [36]. As previously mentioned, many traditional organizations begin the journey into digital transformation in order to keep up in the digital age. Traditional companies with hierarchical processes and systems are good at executing their daily operations but often lack the flexibility to cope with the complexity of the rapid changes in the dynamic world we currently live in [37], this accounts for the airline industry as well.

A department within a large European airline concerned with the digital transformation of its operations in close collaboration with its operational business units was studied. The department was established approximately three years ago. Within this department, six digital transformation initiatives have been studied, together forming the embedded cases. These six DTIs cover various divisions in the airline industry. Every DTI studied has a different employee population and all DTIs are Business to Employee (B2E) initiatives. DTIs are executed according to an agile way of working, using the Scrum framework. The objective of all DTIs was to bring digital solutions into the airline's operations and enable and empower the airline and its employees in their daily activities. 18 semi-structured interviews have been conducted, divided over three employee roles: The Product Manager (PM), The Product Owner (PO), and a Keyuser $(\mathrm{K})$.

\subsection{Research Design}

This study is a cross-sectional empirical exploration of an embedded case study. The data is retrieved in a specific time period (cross-sectional), the largest part of the data is qualitative (empirical) and involves purposive sampling and a specific selection of a phenomenon (case studies). Case studies are generalizable to theoretical propositions, not to universes or populations [38]. This implies that the aim of this research is to expand and generalize the understanding of DTI success criteria and not statistical generalization. Qualitative research is a valuable method for understanding, interpreting, and making sense of how something occurs within a specific context [39, 40]. Qualitative research also provides the tools to examine and articulate the process of how a phenomenon of interest unfolds from the perspective of the individuals themselves [41]. This approach has proven to be most rewarding in examining complex interactions between organizations, technologies and people [42 - 44].

\subsection{Research Instruments \& Procedures}

We used a combination of deductive and inductive reasoning research in our multi-method design. We also used triangulation [45], since our data came from three sources: semi-structured interviews, document analysis and direct observations We used a combination of purposeful and relevance sampling for acquiring respondents, since job description and level play an important role for acquiring different perspectives. Two of the authors worked full-time at the digital transformation department during the research, therefore a considerable amount of inside information was acquired and collected.

The data collection took place between January 2018 and May 2018. The semi-structured interviews started with an introduction of the interviewee, in which they clarified their job role and explained the situation before and after the DTI. Following this, the interviewees were asked for an explanation about their expectations of the DTI; the initial success criteria; the extent to which they were met and their definition of DTI success (1). Secondly, interviewees were asked questions regarding the metrics they had used for expressing DTI success (2), along with what was successful about the digital solution (3). Finally, interviewees were asked about the new collaboration between PM/PO/K during a DTI (4). For the document analysis, the Capital Investment (CI) document, traditional business plans and a few employee journeys were studied. Gatherings and artifacts from the Scrum framework such as retrospectives, demos and plan boards were researched through direct observations [14]. To complete triangulation, the Vice President, founder and lead of the digital transformation department was interviewed to validate and discuss previous findings. The data collected from semi-structured interviews were recorded and transcribed manually. The data was then analyzed using QRS NVivo 12 [46]. 
Table 1: Overview DTI initiatives

\begin{tabular}{|c|c|c|c|c|}
\hline $\begin{array}{c}\text { Case } \\
\text { Number }\end{array}$ & Business Unit & Population & Start DTI & Case study description \\
\hline 1. & $\begin{array}{l}\text { Ground } \\
\text { Services }\end{array}$ & $\begin{array}{c}\text { Shift } \\
\text { leaders } \\
\text { platform }\end{array}$ & 2016 & $\begin{array}{l}\text { Enabling turn-around coordinators to handle incoming } \\
\text { and outbound flights in a more efficient and effective } \\
\text { way by providing them with a state-of-the-art mobile } \\
\text { solution, including real time information concerning the } \\
\text { entire handling flow in a single overview. }\end{array}$ \\
\hline 2. & $\begin{array}{c}\text { Ground } \\
\text { Services, } \\
\text { Cargo, } \\
\text { Engineering \& } \\
\text { Maintenance }\end{array}$ & $\begin{array}{l}\text { Ground } \\
\text { Staff }\end{array}$ & 2017 & $\begin{array}{l}\text { Enabling all ground staff having real-time insights in } \\
\text { rosters and the ability to change the roster, and in parallel } \\
\text { enabling the organization to optimize for workload and } \\
\text { staff planning. }\end{array}$ \\
\hline 3. & Cargo & $\begin{array}{l}\text { Warehouse } \\
\text { Staff }\end{array}$ & 2016 & $\begin{array}{l}\text { Making traditional freight acceptance and shipping } \\
\text { process including a wide variety of systems and high } \\
\text { amounts of paper digital by empowering operational } \\
\text { staff with a mobile device and accompanying app. }\end{array}$ \\
\hline 4. & $\begin{array}{c}\text { Engineering \& } \\
\text { Maintenance }\end{array}$ & Mechanics & 2016 & $\begin{array}{l}\text { Increasing hands-on-metal time of aircraft mechanics by } \\
\text { making paper plan boards and task distribution digital } \\
\text { and empower mechanics with context relevant } \\
\text { information, including party information, manuals and } \\
\text { instructions. }\end{array}$ \\
\hline 5. & $\begin{array}{l}\text { Inflight } \\
\text { Services }\end{array}$ & $\begin{array}{l}\text { Cabin } \\
\text { Crew }\end{array}$ & 2015 & $\begin{array}{l}\text { Empowering cabin crew with a digital device with } \\
\text { context relevant flight, product and passenger } \\
\text { information, enabling an improved customer experience } \\
\text { on board. }\end{array}$ \\
\hline 6. & $\begin{array}{c}\text { Flight } \\
\text { Operations }\end{array}$ & $\begin{array}{l}\text { Cockpit } \\
\text { Crew }\end{array}$ & 2015 & $\begin{array}{l}\text { Improving operational efficiency by enabling a paperless } \\
\text { cockpit, by equipping pilots with a digital device } \\
\text { including relevant passenger and operational } \\
\text { information, roster changes and reporting abilities. }\end{array}$ \\
\hline
\end{tabular}

\section{Results}

The data from the interviews show that the majority of respondents acknowledge that success criteria evolve during the DTIs. The findings from 18 interviews with key respondents support proposition PO - Success criteria evolve during DTIs.

\subsection{Stakeholder View - Traditional Business Case Proposal}

Each DTI had a clear formulated goal concerning its outcome, however the journey towards reaching this goal was flexible. A product owner mentioned: "The end goal was always clear, however, the journey towards reaching this goal changed many times along the way. What bothered me is that executives

do not understand how costly and how much time it takes to develop a specific feature". Due to an insufficient comprehension of technology, and in some cases the lack of agility of executives, the results did not always correspond to expectations.

In almost all of the cases, interviewees stressed that acquiring funding for a DTI happened in a very traditional manner and was not agile at all. A product manager explained: "We did not meet our initial success criteria expressed in KPI's, and this is largely due to the fact that at the approval we needed to apply for a budget, but since applying for budgets happened in a more traditional way, we promised a lot of benefits that we eventually did not reach". Even though the initial success criteria were not met, most DTIs were still regarded as successful since undertaking a DTI was seen as a learning process. As a project manager in Case 1 explained: "Of course, it is a shame that we did not manage to do it in the time frame and budget we agreed on, but we did make it in the end. Part of the money is spent on the fact that everything was new to us and we needed to learn, let 
us call it entry-or discovery money. If we will do it again, we will probably spend less since we now know better about what to expect" (Case 1, PM).

Most cases show that initial success criteria were not met. However, there was one case that did not start according to the traditional way of writing a proposal and acquiring funding to execute the plan. This DTI is the most recent one, and started a year ago. "We did not apply for a budget yet since this DTI existed in a more organic way due to a sense of urgency, also our team is still relatively small so we do not need that much funding yet" (Case 2, PM). This was the first DTI that started off as an initiative from within the digital transformation department, instead of being commissioned by external sub-units. Another possible explanation could be that the digital transformation department had matured over time, and had proven its existence for being able to bring value to the organization. Even though the majority of the interviewees were able to formulate a clear goal of the DTI, they were not sure when this goal was reached or when a DTI was finished. Some mentioned that a DTI will never come to an end since they always see or find new opportunities, or something that can be improved, implying that a DTI does not have a specific end goal and its success will emerge along the way. "People ask me quite often, when is the DTI finished? Well, I personally feel it is an ongoing process and I doubt if it will ever be finished" (Case 4, PO). Moreover, keyusers push the bar when it comes to deciding on DTI success. "I am so grateful with the new digital solution since it saves me so much time and gives me independence, however it will be even better if the development team will add more features so I got everything in one place, that will make my life and work easier" (Case 2, K). Another respondent echoed this and added: "The dot on the horizon? I do not think it exists, we go towards this dot and when we are there, we set a new one" (Case $5, \mathrm{~K})$. These quotes show that even though the initial success criteria were not met, a DTI could still be regarded as successful. A DTI is described as an ongoing process and its success will emerge along the way. The findings from our interviews indicate support for $P 1$ - DTI success criteria evolve more when the proposal at the approval stage derives from traditional business cases.

\subsection{Stakeholder View - Different Metrics}

The interview results indicate that most interviewees use different metrics to indicate the success or progress of a DTI. The respondents within this study referred to a large number of different indicators or variables to explain the success or progress of a DTI, for example: sprints, stakeholder meetings, retrospectives, demo presentations, adoption percentages, employee journeys, number of features or key performance indicators (KPI's). Product managers referred mostly to the initial success criteria or employee journeys, whereas most product owners expressed their DTI success in the number of features they delivered or the number of sprints they managed to fulfill. Meaning that DTI success is expressed in different dimensions by different stakeholders.

Overall, product owners are more concerned with output (e.g. the number of features that were developed), while key-users were more concerned with product readiness. In some cases, the old way of working still existed next to the new way of working which lead sometimes to low adoption rates of the new digital solution. Key-users stressed that in their view most digital solutions were 'not ready' to use for work yet, since it was not capable of doing all the things that their previous system could do. One of them said: "It was hard that we needed to wait for an update every time, we were not able to do all of our daily tasks with the minimum viable product (MVP). We are used to working with a system that is able to do everything, which makes it unattractive for us to make the switch to a new solution that is not ready yet". Some Product Owners spoke about a reason for tension as they were not able to improve their product outcomes effectively because end-users were waiting for the product to mature. "Some employees are not using the tool because they think it is not 'ready' yet. However, they should work with it in order for our development team to improve the digital tool through feedback, this is a serious challenge we are currently facing" (Case 4, PO)".

In summary, since all key stakeholders use different metrics to express DTI success, it might be hard to explain and come to an agreement about 'when' a DTI is considered as successful and 'what' it is that makes it successful. This means we found support for $P 2$ - Different stakeholders $(P M / P O / K)$ express DTI success in different metrics.

\subsection{Product vs Process - Digital Solution}

Working with a new digital solution brings various emerging success variables, in most cases the old way of working, mostly paper-based processes, are 
replaced with an application through which the information is now collected and distributed and, if possible, made actionable. The initial success criteria focus more on measurable benefits, such as process efficiency, customer benefits or cost reductions. The following quotes show that employees express their ideas of success that derive from the digital solution in other, more qualitative variables.

In the old way of working, not all employees had the same access to information or data. Part of the hierarchy and strict boundaries between job roles diminished since all employees who carry out a specific task, have the same solution with the same access to data. This brings a new dimension to their job role: responsibility. This new level of responsibility has two consequences. First, employee empowerment is a concept that almost all respondents highlighted during our interviews. "I feel much more in control now I work with this new tool since it is so easy to report, and I do not need assistance or permission from others anymore before taking action" (Case 4, K). This new form of responsibility comes with an extra challenge since it asks for a different and more proactive attitude from an employee to make it even more successful, which is not always clear to them. "Sometimes it is very unclear what is expected from us, what does the business want? How do they want us to work with the amount of data and information we receive, it is a bit confusing since it is not always possible to do so" (Case 5, K).

Some of the interviewees mentioned that an increased amount of reporting positively influenced safety, which is typically difficult to measure. "We notice a lot of benefits on safety and compliance since people have access to the right information during the right time, which increases data-driven decision making. This also flows from an increase in reporting" (Case 1, PM). Another success variable that became apparent during interviews was employee engagement. Employees are now equipped with iPads which makes asking them for feedback or providing them with last minute changes or information easier. "Employees know now prior to their flight who they are going to work with, this is great for team building. However, we can only earn money on two topics: customer benefits or reducing costs. But in my opinion, employee engagement is important too and it benefits your customer ratings as well, but in a different way." (Case 5, PO). Another success criteria that emerged continuously from the digital solution was joy. "One of the most valued features by crew members, that actually started off as a joke, is that they can see in advance if it is a passengers' birthday on a flight. They really enjoy and appreciate this new form of interaction with passengers" (Case 5, PO). A program manager mentioned that these successes are easily observed since they include direct client interaction. Case 5 and 6 involved less technical operations, it concerned professions that have a direct interaction with customers. "It is much easier to connect commercial benefits to a digital solution when there is direct visibility and contact with our customer, since we receive immediate feedback." (Case 5/6, $\mathrm{PM})$. In conclusion, our data supports $P 3$ - The degree to which key-users embrace the digital solution triggers stronger evolving success criteria.

\section{4. $\mathrm{PM} / \mathrm{PO} / \mathrm{K}$ Collaboration}

The switch from traditional project management to a more agile way of working changed the dynamics between blue- and white-collar employees. The interviewees, the key-users in particular, talked at length about their recognized position as key-user in this new process of developing a new digital solution. "Before this DTI, there were loads of other projects that tried to help us, it all started with good intentions, but over time, interest was starting to fade until the project was terminated before it was even finished. Now we are constantly improving our digital solution, and product owners keep including us in this process" (Case 1, K). It was clearly notable how enthusiastic key-users were, about taking on this new role as cocreators of their own digital solution. However, having key-users as co-creators also brought new challenges when it came to prioritizing features of the product. "Sometimes we do not always agree on interests and priorities, we are constantly looking for the boundary between 'what does our employee really need' and what is 'nice to have' in circumstances like these, prioritizing is based on what is best for the bigger picture" (Case 4, PM). This was a returning dilemma in most cases.

What came up repeatedly was how important a sense of ownership and commitment was for making a DTI successful. "Returning themes of the past few years are commitment and ownership, in the end that is most important. You need ownership and commitment from both sides, shaping the product together, making decisions together, building a vision, it is all a two-way street" (Case 6, PO). Another product owner added: "The involvement and especially faith of the key-users in our product has been crucial for the successful adoption of the new 
digital solution" (Case 3, PO). This new dynamic in collaboration between blue and white-collar employees positively influenced trustworthiness from both sides. "Unlike the old days, we now offer our users the opportunity to give feedback to what we develop for them, this really increases their trust in us but also in the application, we see a clear rise in their appreciation towards us and it gives us assurance about the quality of our work as well" (Case 5, PO). Our data supports P4 - Success criteria evolve more when the collaboration between $P M / P O / K$ is closer during a DTI.

When discussing all of the above findings with the Vice President, she said the following: "When are we really successful? If we see that our digital investment is positively influencing our customer loyalty, when we reduce costs and also bring joy to our people. Many positive benefits were not thought of upfront during a DTIs approval, and because they were not documented they are not recognized. Making this translation is the complex duty that I do, since we are still stuck in old processes, but I fully believe that we can make it happen. It is my task to say, "I will take the blame", in case anything goes wrong, by doing so and offering this security, I am sure more successes will follow along the way" (VP).

\section{Discussion and Future Research}

\subsection{Contribution to Theory}

This study investigated six embedded cases within different sub-units of a single airline company in order to understand how and why success criteria of DTIs evolve. The findings show how the following contribute to evolving success criteria: traditional business case approval practices, the degree of involvement of different stakeholders, the closeness in collaboration between these stakeholders and lastly the degree to which key-users embrace the digital solution during the DTI.

The findings show the complexities and challenges but also the opportunities when it comes to defining (and redefining) the success of a DTI from the early planning and approval phase throughout its 'life' as a DTI. Approaching a DTI as a TT, taking the accompanying processes and practices into account, helps to understand why and how DTI success criteria change. Our research thus shows how TT literature [19], with its roots in sociology, complements and strengthens existing insights into the influence and perspectives of stakeholders on relatively open-ended initiatives such as DTI.

\subsection{Implications for Practice}

The decision to undertake a digital transformation can bring many unforeseen benefits, as illustrated in our case studies. Initial goals, often agreed upon as part of more rigid business case approval practices, can move to the background or become irrelevant due to new insights that emerge, often as a result of the involvement and experimentation of users and other stakeholders. This can (and does) lead to problems when management revisits business case promises only to find out that these no longer apply.

Understanding the TT nature of a DTI, already during the planning and approval stage, will help to reduce these problems. A more open and qualitative approach when (re)defining digital transformation success and a more agile approach to business case approval processes will also be beneficial. Including (key) users and other stakeholders and having them experiment with the new technology and encouraging them to help shape the DTI as it progresses is also likely to lead to new and often unplanned 'net benefits'. This is challenging in organizations that embrace an 'agile' way of working for DTIs but are more traditional when it comes to budget and business case approval processes.

\subsection{Limitations and Future Research}

This paper is based on six case studies within a single company, and as such there are clear limitations in terms of generalization. At the same time, this offered some control over external factors, and in many ways this company shares characteristics with other large and organizations embarking on a digital transformation. Future research should include different types of organizations.

Digital Transformations are inherently multidisciplinary in nature, involving IT, change management and other areas. Our literature review only considered the important theories from the IS scholars basket of 8 IS journals. Future research could consider important DT theories from other fields within business studies but also disciplines like sociology.

In this study, only DTIs with an agile way of working were researched, which is common but not always the case. Likewise, other possible explanations for the existence of emerging success criteria during 
DTIs should be considered in order to develop a deeper and further understanding of the phenomenon.

\section{References}

[1] "Leading in the Digital Age," Harv. Bus. Rev., pp. 1-10, 2017.

[2] G. Colbert, A., Yee, N. \& George, "The Digital Workforce and the Workplace of the Future," Acad. Manag. J., vol. 59, pp. 731-739, 2016.

[3] D. R. Conner, Managing at the speed of change: how resilient managers succeed and prosper where others fail. Toronto: ON: Random House, 1992.

[4] L. J. Mullins, Management and Organizational Behavior. New Jersey: Prentice Hall, 2005.

[5] M. Beer and N. Nohria, "Cracking the Code of Change," Harv. Bus. Rev., vol. 78, no. 3, pp. 133142, 2000.

[6] J. Kagermann, H. Wahlster, W., Helbig, "Recommendations for implementing the strategic initiative INDUSTRIE 4.0,” 2013.

[7] N. Uchihira, H. Ishimatsu, and K. Inoue, "IoT service business ecosystem design in a global, competitive, and collaborative environment," in PICMET 2016 - Portland International Conference on Management of Engineering and Technology: Technology Management For Social Innovation, Proceedings, 2017, pp. 1195-1201.

[8] B. R. Haverkort and A. Zimmermann, "Smart Industry: How ICT Will Change the Game!," IEEE Internet Comput., vol. 21, no. 1, pp. 8-10, 2017.

[9] C. Klötzer and A. Pflaum, "Toward the Development of a Maturity Model for Digitalization within the Manufacturing Industry's Supply Chain," in 50th Hawaii International Conference on System Sciences, 2017, pp. 42104219.

[10] M. E. Shank, A. C. Boynton, and R. W. Zmud, "Critical Success Factor Analysis as a Methodology for MIS Planning," MIS Q., vol. 9, no. 2, pp. 121-129, 1985.

[11] A. de Wit, "Measurement of project success," Int. J. Proj. Manag., vol. 6, no. 3, pp. 164-170, 1988.

[12] de L. A. Mosconi, E., Packmohr, S., SantaEulalia, "Making Digital Transformation Real," 2018. [Online]. Available:

http:/hicss.hawaii.edu/tracks-52/internet-and-thedigital-economy/\#making-digital-transformationreal-minitrack.

[13] D. Beck, K., Beedle, M., Bennekum, A.,
Cockburn, A., Cunningham, W., Fowler, M., Grenning, J., Highsmith, J., Hunt, A., Jeffries, R., Kern, J., Marick, B., Martin, R., Mellor, S., Schwaber, K., Sutherland, J. and Thomas, "Manifesto for Agile Software Development," 2001. [Online]. Available: http://agilemanifesto.org/iso/en/principles.html. [Accessed: 10-Apr-2018].

[14] J. \& K. S. Sutherland, "Scrum.org," 2017. [Online]. Available: https://www.scrum.org/resources/scrum-guide. [Accessed: 09-May-2018].

[15] K. Liere-Netheler, S. Packmohr, and K. Vogelsang, "Drivers of Digital Transformation in Manufacturing," in Proceedings of the 51st Hawaii International Conference on System Sciences |, 2018, pp. 3926-3935.

[16] L. Willcocks, E. A. Whitley, and C. Avgerou, "The ranking of top IS journals: A perspective from the London School of Economics," Eur. J. Inf. Syst., vol. 17, no. 2, pp. 163-168, 2008.

[17] K. Zhu, S. Dong, S. X. Xu, and K. L. Kraemer, "Innovation diffusion in global contexts: Determinants of post-adoption digital transformation of European companies," Eur. $J$. Inf. Syst., vol. 15, no. 6, pp. 601-616, 2006.

[18] A. Maedche, "Interview with Michael Nilles on "what makes leaders successful in the age of the digital transformation?," Bus. Inf. Syst. Eng., vol. 58, pp. 287-289, 2016.

[19] F. W. Geels, "Technological transitions as evolutionary reconfiguration processes: A multilevel perspective and a case-study," Res. Policy, vol. 31, no. 8-9, pp. 1257-1274, 2002.

[20] C. Freeman, C., Perez, No Structural Crisis of Adjustment, Business Cycles and Investment Behaviour. In: Dosi, G., Freeman, C., Nelson, R., Silverberg, G., Soete, L. (Eds.),Technical Change and Economic Theory. London: Pinter, 1988.

[21] H. Woodward, "Beyond Cost, Schedule and Performance: Project Success as the Customer Sees It," in PMI Global Congress Proceedings, 2005, pp. 1-6.

[22] R. Atkinson, "Project Management: Cost, Time and Quality, two best guesses and a phenomenon, its time to accept other success criteria," Int. J. Proj. Manag., vol. 17, no. 6, pp. 337-342, 1999.

[23] E. R. Petter, S. DeLone, H. Mclean, "Information Systems Success: The Quest for the Independent Variables," J. Manag. Inf. Syst., vol. 29, no. 7, pp. 7-62, 2013.

F. G. Neves, H. Borgman, and H. Heier, "Success 
lies in the eye of the beholder: The mismatch between perceived and real IT project management performance," in Proceedings of the Annual Hawaii International Conference on System Sciences, 2016, vol. 2016-March, pp. 5878-5887.

[25] K. Müller, R. Jugdev, "Critical success factors in projects: Pinto, Slevin, and Prescott - the elucidation of project success," Int. J. Manag. Proj. Bus., vol. 5, no. 4, pp. 757-775, 2012.

[26] J. S. Reel, "Critical Success Factors in Software Projects," IEEE Softw., no. May/June, pp. 18-23, 1999.

[27] G. P. Sudhakar, "A model of critical success factors for software projects," J. Enterpr. Inf. Manag., vol. 25, no. 6, pp. 537-558, 2012.

[28] \& W. Z. Jasperson, J., Carte, T., Saunders, C. Butler, B. Croes, H., "Power and Information Technology Research: A Metratriangulation Review," MIS Q., vol. 26, no. 4, pp. 397-459, 2002.

[29] N. A. Martin, Project Politics: A systematic Approach to Managing Complex Relationships. Surrey, UK: Gower, 2011.

[30] R. G. Cooper, "Stage-Gate Systems: A new tool for managing new products," Bus. Horiz., vol. 33, no. 3, pp. 44-54, 1990.

[31] M. Fitzgerald, M. Kruschwitz, N. Bonnet, D. Welch, "Embracing digital technology: a new strategic imperative," MIT Sloan Manag. Rev., vol. 55 , no. 2 , pp. 1-12, 2014.

[32] W. Delone and E. Mclean, "The DeLone and McLean Model of Information Systems Success: A Ten-Year Update," J. Manag. Inf. Syst., vol. 19, no. 4, pp. 9-30, 2003.

[33] F. Guaragni, T. Schmidt, and K. Paetzold, "Traditional and Agile Product Development in a Hyperconnected World: Turning Weaknesses into Strengths," in Procedia CIRP, 2016, vol. 52, no. September, pp. 62-67.

[34] S. Nerur, R. Mahapatra, and G. Mangalaraj, "Challenges of migrating to agile methodologies," Commun. ACM, vol. 48, no. 5, pp. 72-78, 2005.

[35] E. Pels, "Airline network competition: Full-service airlines, low-cost airlines and long-haul markets," Res. Transp. Econ., vol. 24, no. 1, pp. 68-74, 2008.

[36] H. Min and S. J. Joo, “A comparative performance analysis of airline strategic alliances using data envelopment analysis," J. Air Transp. Manag., vol. 52, pp. 99-110, 2016.
[37] J. P. Kotter, "How the most innovative companies capitalize on today's rapid-fire strategic challenges - and still make their numbers," Harv. Bus. Rev., vol. 90, no. November, pp. 45-58, 2012.

[38] R. K. Yin, "Case Study Research - Design and Methods," Appl. Soc. Rsearch Methods Ser., vol. 5, pp. 8-13, 2006.

[39] M. G. Pratt, Fitting oval pegs into round holes: Tensions in evaluating and publishing qualitative research in top-tier North American journals, vol. 11, no. 3. 2008.

[40] Y. S. Denzin, N.K., Lincoln, Handbook of Qualitative Research. Thousand Oaks, CA: Sage, 2000.

[41] J. Creswell, "Research Design Qualitative, Quantitative and Mixed Methods Approaches," J. Chem. Inf. Model., vol. 53, no. 9, pp. 1689-1699, 2009.

[42] P. Palvia, D. Leary, E. Mao, V. Midha, P. Pinjani, and A. F. Salam, "Research Methodologies in MIS: An Update," Commun. Assoc. Inf. Syst., vol. 14, no. 1, pp. 526-542, 2004.

[43] L. \& G. P. Dubé, "Rigor in Information Systems Positivist Case Research: Current Practices, Trends and Recommendations," MIS Q., vol. 27, no. 4, pp. 597-636, 2003.

[44] G. Walsham, "Doing interpretive research," Eur. J. Inf. Syst., vol. 15, no. 3, pp. 320-330, 2006.

[45] K. M. Eisenhardt and M. E. Graebner, "Theory building from cases: Opportunities and challenges," Acad. Manag. J., vol. 50, no. 1, pp. 25-32, 2007.

[46] E. Welsch, "Welsch, E. (2002). Dealing with data: Using Nvivo in the qualitative data analysis process. In Forum Qualitative Sozialforschung/Forum: Qualitative Social Research (Vol. 3, No.2).," Qual. Soc. Qual. Soc. Res., vol. 3, no. 2, 2002. 